\title{
Perbandingan Kombinasi Bupivakain 0,5\% Hiperbarik dan Fentanil dengan Bupivakain 0,5\% Isobarik dan Fentanil terhadap Kejadian Hipotensi dan Tinggi Blokade Sensorik pada Seksio Sesarea dengan Anestesi Spinal
}

\author{
Ahmado Okatria, ${ }^{1}$ Ezra Oktaliansah, ${ }^{2}$ Tatang Bisri ${ }^{2}$ \\ ${ }^{1}$ SMF Anestesi Rumah Sakit Umum Daerah SMC Kab. Tasikmalaya, \\ ${ }^{2}$ Departemen Anestesiologi dan Terapi Intensif \\ Fakultas Kedokteran Universitas Padjadjaran/Rumah Sakit Dr. Hasan Sadikin Bandung
}

\begin{abstract}
Abstrak
Anestesi spinal mejadi teknik pilihan untuk seksio sesarea karena lebih aman dan efisien dibanding dengan anestesi umum. Anestesi spinal pada wanita hamil menyebabkan hipotensi lebih berat dan cepat. Hipotensi berhubungan dengan ketinggian blokade simpatis yang dipengaruhi oleh barisitas anestetik lokal. Tujuan penelitian ini adalah membandingkan kejadian hipotensi dengan tinggi blokade sensorik antara kombinasi bupivakain 0,5\% hiperbarik 12,5 mg dan fentanil $25 \mu \mathrm{g}$ dengan bupivakain 0,5\% isobarik 12,5 mg-fentanil $25 \mu \mathrm{g}$ pada anestesi spinal untuk seksio sesarea. Penelitian dilakukan di Central Operating Theatre (COT) Rumah Sakit Dr. Hasan Sadikin Bandung selama bulan April-Mei 2015 dengan uji klinis acak tersamar ganda terhadap 40 pasien yang menjalani seksio sesarea dengan status fisik American Society of Anesthesiologist (ASA) II. Kejadian hipotensi dan tinggi blokade sensorik dinilai setelah pemberian anestesi spinal. Data penelitian dianalisis menggunakan uji-t, Mann-Whitney, dan chi-kuadrat. Hasil penelitian bermakna jika nilai $p<0,05$. Kejadian hipotensi antara kelompok hiperbarik dan isobarik adalah $75 \%$ vs $100 \%(p=0,017)$. Tinggi blokade sensorik rata-rata antara kedua kelompok di $\mathrm{T}_{6} \mathrm{vs}_{4} \mathrm{~T}_{4}(\mathrm{p}=0,000)$. Kejadian hipotensi dan blokade sensorik lebih tinggi pada kombinasi bupivakain 0,5\% isobarik 12,5 mg dan fentanil $25 \mu \mathrm{g}$ dibanding dengan bupivakain $0,5 \%$ hiperbarik $12,5 \mathrm{mg}$ dan fentanil $25 \mu \mathrm{g}$.
\end{abstract}

Kata kunci: Anestesi spinal, bupivakain hiperbarik, bupivakain isobarik, seksio sesarea

\section{Comparison between Combination of Hyperbaric 0.5\% Bupivacain with Fentanyl and $0.5 \%$ Isobaric Bupivacain with Fentanyl Use on Incidence of Hypotension and Sensoric Blockade Level in Caesarian Section with Spinal Anesthesia}

\begin{abstract}
Spinal anesthesia technic has been the technic of choice for caesarean section due to its safety and efficiency compared to general anesthesia. Spinal anesthesia in pregnancy causes hypotension in a heavier and more rapid manner. Hypotension is associated with the height of the sympathetic block influenced by the baricity of the local anesthetics. This study aimed to compare hypotension incidence and sensory blockade height between combination of $12.5 \mathrm{mg} 0.5 \%$ hyperbaric bupivacaine with $25 \mu \mathrm{g}$ fentanyl and $12.5 \mathrm{mg}$ 0.5\% isobaric bupivacaine with fentanyl $25 \mu \mathrm{g}$ in spinal anesthesia for caesarean section. The study was performed at the central operating theatre (COT) of Dr. Hasan Sadikin General Hospital during April-May 2015 using double blind randomized control trial method on 40 patients underwent caesarean section with American Society of Anesthesiologist (ASA) II physical status. The hypotension incidence and sensory blockade height were assessed after spinal anesthesia and measured by t-test, Mann Whitney, and Chi-square tests. Significancy was declared when $\mathrm{p}$ value $<0.05$. The hypotension incidence between the hyperbaric and isobaric groups were $75 \%$ vs. $100 \%$ (p value $=0.017$ ). The mean sensory blockade height was at T6 vs. T4 ( $p$ value $=0.000$ ). The hypotension incidence and sensory blockade are significantly higher in isobaric $12.5 \mathrm{mg} 0.5 \%$ bupivacainewith $25 \mu \mathrm{g}$ fentanyl compared to those in $12.5 \mathrm{mg}$ hyperbaric $0.5 \%$ bupivacaine with fentanyl $25 \mu \mathrm{g}$.
\end{abstract}

Key words: Caesarean section, hyperbaric bupivacaine, isobaric bupivacaine, spinal anesthesia

Korespondensi: Ahmado Okatria, dr., SpAn, SMF Anestesi Rumah Sakit Umum Daerah SMC Kab. Tasikmalaya, Jl. Raya Rancamaya Singaparna, Tlpn 0265-543456, Mobile 082126382921,Email okatria@yahoo.com 


\section{Pendahuluan}

Anestesi yang diberikan untuk seksio sesarea dapat berupa anestesi umum maupun regional, namun saat ini anestesi spinal sering dijadikan pilihan utama untuk seksio sesarea dengan kelebihan dan kekurangannya. Anestesi spinal adalah analgesia regional dengan menghambat sel-sel saraf di dalam ruang subaraknoid oleh anestetik lokal yang dilakukan dengan cara memasukkan dosis kecil obat anestesi lokal ke dalam ruangan subaraknoid. Anestesi spinal menjadi pilihan utama karena dinilai aman, memberikan analgesi kuat, relaksasi otot yang cukup, mudah dilakukan, onset cepat, durasi kerja pendek, biaya murah, serta efek samping dan komplikasi lebih sedikit jika dibanding dengan anestesi umum. ${ }^{1,2}$

Hal yang paling sering terjadi akibat anestesi spinal adalah hipotensi yang diakibatkan oleh blokade simpatis. Kejadian hipotensi pada wanita hamil akan lebih berat dan lebih cepat dibanding dengan pasien tidak hamil. Hal ini disebabkan oleh karena uterus menekan vena kava, vena pelvis, aorta, dan juga cabang-cabangnya, hal ini disebut supine hypotensive syndrome. Mortalitas serta morbiditas terhadap ibu dan janin mungkin terjadi pada wanita hamil jika hipotensi tidak diatasi. $^{3}$

Barisitas anestetik lokal merupakan faktor utama yang memengaruhi penyebaran obat di ruang subaraknoid, obat anestesi lokal akan menyebar lebih ke arah sefalad pada barisitas yang lebih rendah sehingga memengaruhi ketinggian blokade saraf simpatis. ${ }^{3,4}$ Barisitas adalah rasio densitas anestetik lokal terhadap densitas cairan serebrospinal. Densitas adalah berat dalam gram dari $1 \mathrm{~mL}$ cairan pada temperatur tertentu. ${ }^{2}$

Cairan serebrospinal memiliki nilai tengah densitas $1,0003 \mathrm{~g} / \mathrm{mL}$ pada suhu $37^{\circ} \mathrm{C}$ dengan rentang 1,0000-1,0006 g/mL. ${ }^{5}$ Anestetik lokal disebut hipobarik bila densitas kurang lebih 3 standar deviasi (SD) di bawah densitas cairan serebrospinal dan disebut hiperbarik bila densitas kurang lebih 3 SD di atas densitas cairan serebrospinal. ${ }^{2}$ Gravitasi menyebabkan anestetik lokal hiperbarik bergerak ke bawah saat di dalam cairan serebrospinal, sedangkan hipobarik sebaliknya. Anestetik lokal isobarik tidak ada efek dari gravitasi atau posisi tubuh. ${ }^{3}$

Secara komersial bupivakain yang tersedia sehari-hari berada dalam bentuk hiperbarik dan isobarik. Bupivakain hiperbarik diberi tambahan larutan dekstrosa sehingga memiliki densitas lebih tinggi dibanding dengan cairan serebrospinal, sedangkan bupivakain isobarik bebas dekstrosa dan memiliki densitas yang sama dengan cairan serebrospinal. Beberapa penelitian sebelumnya menyatakan bupivakain isobarik cenderung bersifat lebih hipobarik terhadap densitas cairan serebrospinal., ${ }^{4,6}$

Penambahan fentanil ke dalam anestetik lokal dapat menurunkan barisitas anestetik lokal tersebut. Fentanil ditambahkan ke dalam anestetik lokal hiperbarik sehingga barisitas menurun, namun tetap hiperbarik, sedangkan jika ditambahkan ke dalam anestetik lokal isobarik maka barisitasnya menjadi hipobarik. Penambahan obat adjuvan yang menyebabkan perbedaan densitas $0,0006 \mathrm{~g} / \mathrm{mL}$ atau lebih dapat memengaruhi arah pergerakan anestetik lokal di dalam cairan serebrospinal. ${ }^{6}$

Penelitian ini bertujuan membandingkan kejadian hipotensi dan tinggi blokade sensorik pemberian kombinasi bupivakain 0,5\% hiperbarik $12,5 \mathrm{mg}$ dan fentanil $25 \mu \mathrm{g}$ dengan bupivakain $0,5 \%$ isobarik $12,5 \mathrm{mg}$ dan fentanil $25 \mu \mathrm{g}$ pada seksio sesarea dengan anestesi spinal.

\section{Subjek dan Metode}

Penelitian ini adalah penelitian eksperimental dengan memakai uji klinik tersamar ganda yang dilakukan setelah mendapat persetujuan dari Komite Etik Penelitian Kesehatan Fakultas Kedokteran Universitas Padjadjaran/Rumah Sakit Dr. Hasan Sadikin Bandung. Penelitian dilakukan padabulan April-Mei 2015 di Rumah Sakit Dr. Hasan Sadikin Bandung dengan kriteria inklusi adalah wanita hamil dengan status fisik American Society of Anesthesiologist (ASA) II yang akan menjalani seksio sesarea elektif atau segera dengan anestesi spinal, usia di atas 16 tahun, usia kehamilan lebih dari 36 minggu, tinggi badan $150-170 \mathrm{~cm}$, dan berat 
badan 50-80 kg. Kriteria eksklusi adalah kehamilan gemeli, polihidramnion, plasenta previa, pasien yang memiliki riwayat alergi terhadap obat-obatan yang digunakan dalam penelitian ini, serta pasien dengan kelainan tulang belakang. Sampel dikeluarkan apabila terjadi kegagalan pada tindakan anestesi spinal setelah ditunggu selama 15 menit, terjadi perdarahan yang tidak dapat diatasi, dan anestesi spinal dialihkan menjadi anestesi umum.

Penentuan besar sampel digunakan rumus perbedaan dua proporsi efektivitas antara dua tindakan dengan tingkat kepercayaan $(\alpha)$ 95\% dan besarnya uji kekuatan $80 \%$. Besar sampel minimal yang dibutuhkan minimal 20 subjek untuk setiap kelompok. Sampel diambil secara acak dengan permutasi yang dibagi menjadi 2 kelompok dengan setiap kelompok terdiri atas 20 pasien. Kelompok I adalah kombinasi bupivakain $0,5 \%$ hiperbarik $12,5 \mathrm{mg}$ dan fentanil $25 \mu$, sedangkan kelompok II adalah kombinasi bupivakain 0,5\% isobarik 12,5 mg dan fentanil $25 \mu$ g.

Alat pantau dipasang pada tubuh pasien dan dicatat data tekanan darah, laju nadi, elektrokardiogram (EKG), dan saturasi oksigen perifer. Pasien dipasang infus dengan kateter intravena 18G, diberikan premedikasi ranitidin $50 \mathrm{mg}$ intravena (i.v.) dan metoklopramid 10 mg i.v. 30 menit sebelum tindakan anestesi. Pasien diberi cairan ringer laktat (RL) $20 \mathrm{~mL} /$ $\mathrm{kgBB}$ yang habis dalam 20 menit, dilanjutkan $20 \mathrm{~mL} / \mathrm{kgBB} / \mathrm{jam}$ sebagai cairan pemeliharaan. Pasien diposisikan duduk membungkuk dan dilakukan aseptik dan antiseptik memakai povidon iodin dan alkohol $70 \%$. Anestesi spinal dilakukan menggunakan jarum spinal Quincke no. 25G yang ditusukkan di atas garis Tuffier $\left(\mathrm{L}_{3-4}\right)$ yang merupakan garis imajiner titik perpotongan tulang vertebra dengan spina iliaka anterior superior (SIAS) dengan bevel jarum spinal menghadap ke lateral.

Saat didapatkan aliran cairan serebrospinal yang jernih, bevel jarum diputar ke arah kepala, kemudian anestetik lokal disuntikkan dalam waktu 15 detik. Setelah anestetik lokal selesai disuntikkan, pasien dibaringkan pada posisi datar terlentang dengan diganjal bantal di bokong kanan. Pasien diberikan oksigen 3 L/menit melalui nasal kanula.

Tekanan darah, laju nadi, dan juga saturasi oksigen perifer diukur setiap 1 menit setelah penyuntikan selesai selama 20 menit pertama, selanjutnya dilakukan setiap 2,5 menit hingga operasi selesai. Kejadian hipotensi diatasi dengan memberikan efedrin 5-10 mg i.v., bila bradikardia diberikan sulfas atropin $0,5 \mathrm{mg}$ i.v., dan mual muntah diberikan ondansentron $4 \mathrm{mg}$ i.v.

Tes Pinprick dilakukan sejajar dengan garis tengah klavikula yang dimulai dari vertebra $\mathrm{T}_{10}$ dilakukan bertahap ke arah sefalad sampai didapatkan kriteria Hollmens $\geq 2$ pada daerah dermatom tertinggi. Operasi dapat dimulai bila telah terjadi analgesia pada daerah operasi. Pemantauan tinggi blokade sensorik dengan pinprick dilakukan setiap 3 menit sampai 15 menit setelah penyuntikan. Daerah dermatom tertinggi yang memenuhi kriteria Hollmens

Tabel 1 Karateristik Umum Pasien

\begin{tabular}{lccccc}
\hline \multirow{2}{*}{ Karakteristik Responden } & \multicolumn{2}{c}{ Hiperbarik (n=20) } & \multicolumn{2}{c}{ Isobarik (n=20) } & \multirow{2}{*}{ Nilai p } \\
\cline { 2 - 5 } & Rata-rata & SD & Rata-rata & SD & \\
\hline Usia (tahun) & 30,75 & 5,55 & 28,85 & 6,63 & $0,357^{*}$ \\
Tinggi badan (cm) & 156,80 & 2,19 & 156,35 & 2,13 & $0,508^{*}$ \\
Berat badan (kg) & 66,95 & 5,74 & 68,15 & 7,94 & 0,587 \\
Body mass index $\left(\mathrm{kg} / \mathrm{m}^{2}\right)$ & 27,23 & 1,79 & 27,88 & 3,02 & 0,417 \\
Lama operasi (menit) & 50,60 & 9,70 & 47,90 & 7,20 & 0,283 \\
\hline
\end{tabular}

Keterangan: uji statistik dengan uji-t dan Uji Mann-Whitney*. Bermakna jika nilai $p<0,05$ 
Ahmado Okatria: Perbandingan Kombinasi Bupivakain 0,5\% Hiperbarik dan Fentanil dengan Bupivakain 0,5\% Isobarik dan Fentanil terhadap Kejadian Hipotensi dan Tinggi Blokade Sensorik pada Seksio Sesarea dengan Anestesi Spinal

Tabel 2 Efek Samping Anestesi Spinal pada Kelompok Masing-masing

\begin{tabular}{|c|c|c|c|c|}
\hline \multirow[b]{2}{*}{ Efek Samping } & \multicolumn{2}{|c|}{ Kelompok } & \multirow{2}{*}{$\begin{array}{c}\text { Total } \\
(n=40)\end{array}$} & \multirow[b]{2}{*}{$\mathbf{p}$} \\
\hline & $\begin{array}{c}\text { Hiperbarik } \\
(\mathrm{n}=20)\end{array}$ & $\begin{array}{c}\text { Isobarik } \\
(n=20)\end{array}$ & & \\
\hline Bradikardia & 0 & 0 & 0 & --- \\
\hline Desaturasi oksigen & 0 & 1 & 1 & 0,311 \\
\hline Mual muntah & 5 & 13 & 18 & 0,011 \\
\hline
\end{tabular}

Keterangan: analisis statistik berdasarkan uji chi-kuadrat. Bermakna jika nilai $\mathrm{p}<0,05$

$\geq 2$ merupakan tinggi blokade sensorik yang diukur pada penelitian ini.

Data dianalisis memakai program statistical product and service solution (SPSS) 20,0 for windows. Analisis statistik data hasil penelitian dalam bentuk data numerik menggunakan uji-t bila data berdistribusi normal, sedangkan jika data tidak berdistribusi normal memakai Uji Mann-Whitney dengan tingkat kepercayaan $95 \%(\alpha=5 \%)$. Analisis statistika data kategorik digunakan uji chi-kuadrat dan nilai $\mathrm{p}<0,05$ dianggap bermakna secara statistika.

\section{Hasil}

Penelitian ini dilakukan terhadap 40 pasien yang dibagi ke dalam 2 kelompok, tiap-tiap kelompok terdiri atas 20 pasien. Hasil analisis statistika menggunakan uji-t dan Uji MannWhitney menunjukkan bahwa usia, tinggi badan, berat badan, body mass index (BMI), dan lama operasi pada kedua kelompok perlakuan tidak terdapat perbedaan bermakna $(p>0,05$;
Tabel 1).

Angka kejadian hipotensi pada kelompok hiperbarik dialami oleh 15 dari 20 pasien, sedangkan pada kelompok isobarik dialami semua pasien. Analisis menggunakan uji chikuadrat diperoleh hasil statistika bermakna ( $p=0,017$; Gambar 1). Analisis statistik dengan uji chi-kuadrat didapatkan ketinggian blokade sensorik rata-rata pada kelompok hiperbarik pada $\mathrm{T}_{6}$, sedangkan kelompok isobarik ratarata setinggi $\mathrm{T}_{4}$ dengan perbedaan bermakna $(\mathrm{p}<0,05$; Gambar 2).

Penggunaan dosis efedrin rata-rata antara kelompok hiperbarik dan isobarik adalah 7,3 mg vs 22,5 mg yang bermakna secara statistika $(p<0,05)$. Temuan lain diperoleh efek samping anestesi spinal seperti bradikardia, desaturasi oksigen, dan mual muntah. Tidak ditemukan kejadian bradikardia pada penelitian ini, namun didapatkan kejadian desaturasi oksigen pada seorang pasien dari kelompok isobarik, tetapi berdasarkan statistika tidak bermakna $(p=0,311)$. Mual dan muntah dialami oleh

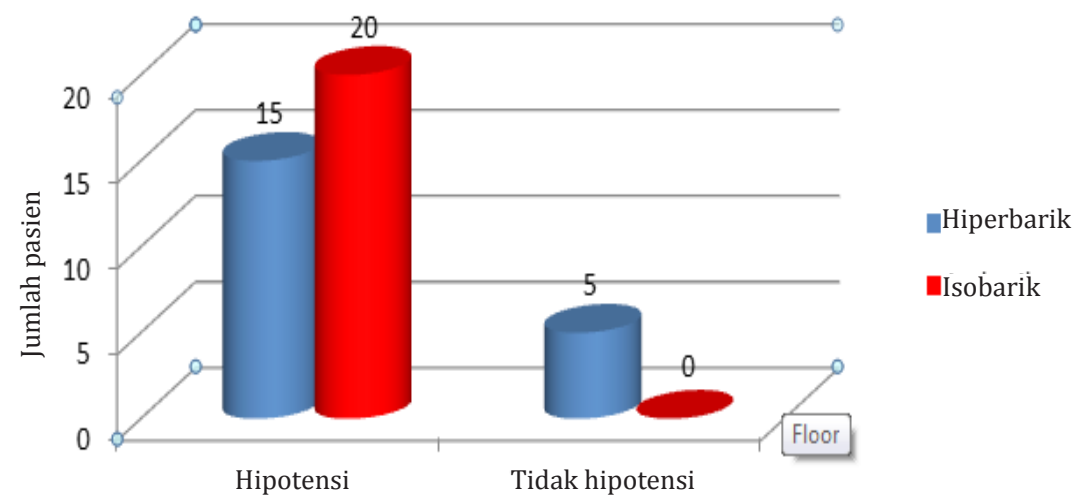

Gambar 1 Kejadian Hipotensi antara Kedua Kelompok 


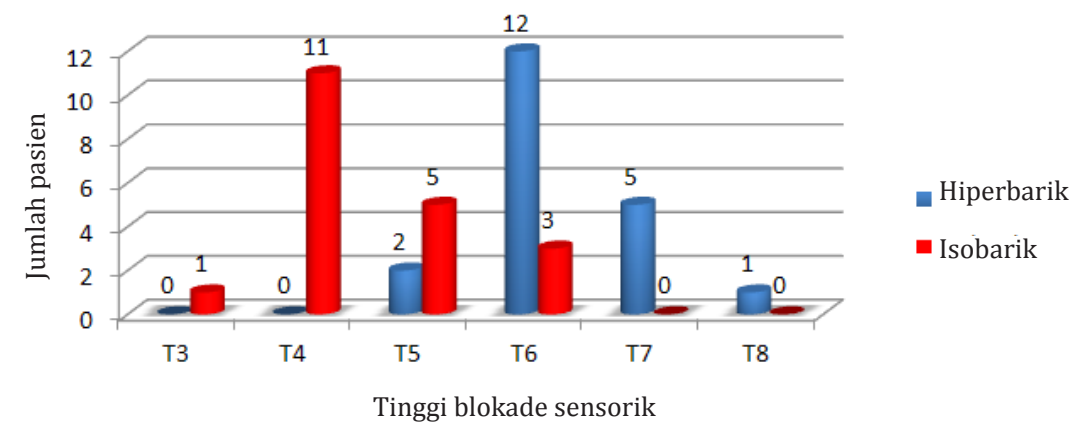

Gambar 2 Perbandingan Tinggi Blokade Sensorik antara Kedua Kelompok

5 pasien dari kelompok hiperbarik dan 13 pasien dari kelompok isobarik (Tabel 2).

\section{Pembahasan}

Karakteristik umum kedua kelompok tidak ada perbedaan bermakna dalam hal usia, tinggi badan, berat badan, BMI, dan lama waktu operasi (Tabel 1). Hal ini menunjukkan bahwa sampel penelitian ini homogen sehingga layak untuk diperbandingkan.

Hipotensi didefinisikan sebagai penurunan tekanan darah sistol $<90 \mathrm{mmHg}$ atau $\geq 20 \%$ dari tekanan darah awal (rata-rata dari 2 kali pengukuran sebelum tindakan anestesi spinal dilakukan). Kejadian hipotensi pada kelompok hiperbarik dialami oleh 15 dari 20 pasien, sedangkan pada kelompok isobarik dialami oleh seluruh pasien (Gambar 1). Analisis statistika dengan uji chi-kuadrat didapatkan nilai $\mathrm{p}=0,017$ sehingga dianggap bermakna.

Ketinggian blokade sensorik tertinggi pada kelompok hiperbarik berada di $\mathrm{T}_{5}$ dengan rata-rata di $\mathrm{T}_{6}$, sedangkan blokade sensorik tertinggi kelompok isobarik berada di $\mathrm{T}_{3}$ dengan rata-rata di $\mathrm{T}_{4}$. Perbedaan ketinggian blokade tersebut diuji dengan uji chi-kuadrat dengan hasil yang bermakna secara statistika ( $\mathrm{p}<0,05$; Gambar 2).

Terdapat 3 faktor yang paling memengaruhi tingkat penyebaran anestetik lokal di ruang subaraknoid, yaitu barisitas anestetik lokal, posisi pasien selama dan sesudah penyuntikan, serta dosis anestetik lokal. Bupivakain adalah anestetik lokal yang sering digunakan untuk anestesi spinal. Secara komersial bupivakain tersedia dalam bentuk hiperbarik dan juga isobarik. ${ }^{3,4}$ Penelitian sebelumnya menemukan bahwa bupivakain isobarik bersifat hipobarik dan fentanil yang sering dipergunakan sebagai adjuvan juga bersifat hipobarik bila dibanding dengan cairan serebrospinal. Kombinasi ini menyebabkan anestetik lokal menjadi lebih hipobarik sehingga anestetik lokal bergerak melawan gravitasi. ${ }^{6}$

Penelitian yang telah lalu membandingkan perbedaan tinggi blokade sensorik anestesi spinal yang dilakukan dalam posisi duduk dan lateral untuk seksio sesarea mempergunakan kombinasi bupivakain yang berbeda barisitas (hiperbarik, isobarik, atau hipobarik) dan diamorfin. Perbedaan barisitas anestetik lokal tidak memengaruhi tinggi blokade sensorik saat anestesi spinal dilakukan dalam posisi lateral, namun menghasilkan perbedaan yang bermakna pada saat anestesi spinal dilakukan dalam posisi duduk. Anestetik lokal hiperbarik bergerak sesuai arah gravitasi, isobarik tidak dipengaruhi gravitasi, sedangkan hipobarik melawan gravitasi sehingga didapatkan bahwa penyebaran anestetik lokal hipobarik lebih tingi dibanding dengan isobarik dan hiperbarik. Tinggi blokade sensorik pada penelitian ini yang dihasilkan anestetik lokal isobarik lebih tinggi, kemungkinan disebabkan oleh anestetik lokal isobarik yang sebenarnya bersifat sedikit hipobarik dan akan semakin hipobarik ketika ditambahkan fentanil sehingga anestetik lokal akan bergerak melawan gravitasi karena pada penelitian ini pasien diposisikan duduk saat penyuntikan. ${ }^{4,7}$ Jumlah kejadian hipotensi juga lebih tinggi terjadi pada bupivakain dengan 
barisitas lebih rendah, ${ }^{4,7,8}$ walaupun terdapat beberapa penelitian yang berdasarkan analisis statistika ternyata tidak terdapat perbedaan bermakna. ${ }^{9,10}$

Dosis anestetik lokal juga memengaruhi penyebaran anestetik lokal di dalam ruang subaraknoid setelah penyuntikan. Konsentrasi anestetik lokal yang bercampur dengan cairan serebrospinal menghasilkan konsentrasi baru. Anestetik lokal yang sering digunakan antara lain tetrakain (7-10 mg), lidokain (50-60 mg), atau bupivakain $(10-15 \mathrm{mg}){ }^{1}$

Kebutuhan obat anestesi lokal pada wanita hamil berkurang sebagai akibat pelebaran vena epidural karena pembesaran uterus dan juga penekanan vena kava. Hal ini mengakibatkan jumlah cairan serebrospinal berkurang dan meningkatkan penyebaran anestetik lokal ke sefalad. ${ }^{11}$

Pada penelitian sebelumnya menggunakan bupivakain berbeda barisitas dengan dosis 10 mg ternyata gagal mendapatkan perbedaan bermakna secara statistika terhadap kejadian hipotensi dan juga tinggi blokade sensorik..$^{9,10}$ Bupivakain hiperbarik, isobarik, dan hipobarik mampu menghasilkan tinggi blokade sensorik yang adekuat untuk operasi dengan risiko hipotensi yang sama di setiap kelompoknya. Penggunaan dosis bupivakain 12-15 mg atau penambahan obat adjuvan sufentanil ternyata menghasilkan perbedaan terhadap kejadian hipotensi serta tinggi blokade sensorik yang bermakna secara statistika. ${ }^{7,8}$

Selama bertahun-tahun efedrin merupakan vasopressor pilihan untuk mengatasi hipotensi pada seksio sesarea. Alasannya adalah karena efedrin mempunyai efek beta adrenergik yang kuat dan alfa adrenergik yang lebih lemah. Penggunaan efedrin akan meningkatkan curah jantung, denyut jantung, serta tekanan darah sistol dan diastol. Aliran darah ke splanchnic dan ginjal akan menurun, namun aliran darah ke jantung, serebral, dan juga otot meningkat. ${ }^{12}$ Pada penelitian ini, pasien yang didapatkan dalam kondisi hipotensi diberikan efedrin sebanyak 5-10 mg secara i.v., dan hasil akhir penggunaan dosis efedrin rata-rata adalah 7,3 mg pada kelompok hiperbarik dan 22,5 mg pada kelompok isobarik.
Efek samping yang dapat ditimbulkan oleh anestesi spinal adalah bradikardia, desaturasi oksigen, mual, dan muntah. ${ }^{3}$ Pada penelitian ini tidak didapatkan kejadian bradikardia. Bradikardia sebagian disebabkan oleh tonus parasimpatis yang berlebihan akibat blokade serabut saraf simpatis cardio accelerator $\mathrm{T}_{1}-$ $\mathrm{T}_{5}$, tetapi sebab utamanya adalah penurunan preload. Penurunan preload akan mengaktifkan kelompok refleks yang bertanggung jawab terhadap regangan volume intrakardiak dan atau reseptor pacemaker. Penurunan volume ventrikel secara tiba-tiba akan menyebabkan bradikardia berat dan asistol melalui aktivitas paradoksal refleks Bezold-Jarisch. Bradikardia diterapi bila denyut nadi $\leq 50 \mathrm{x} /$ menit. $^{13}$

Anestesi spinal hanya memberikan sedikit pengaruh terhadap fungsi pulmonal pada pasien yang sebelum operasi tidak mengalami gangguan paru. Pada penelitian ini, desaturasi oksigen hingga $80 \%$ yang berlangsung lebih dari 30 detik didapatkan pada kelompok isobarik. Hal tersebut disebabkan oleh spinal tinggi dapat menyebabkan pasien kesemutan atau kelemahan pada tangan atau bahu, mual dengan atau tanpa muntah, serta kesulitan bicara, menelan hingga bernapas. Blokade yang terlalu tinggi berhubungan dengan paralisis otot interkostal yang menyebabkan dinding dada menjadi tidak stabil dan mengakibatkan penurunan fungsional residual capacity (FRC) sebesar 0,5-1 liter. ${ }^{14}$ Otot abdominal juga terganggu menyebabkan gangguan fungsi ventilasi sehingga pasien mengalami sesak dan peningkatan ventilasi per menit. ${ }^{3,14}$ Spinal tinggi sering dikaitkan dengan dosis anestesi lokal yang besar, namun sering juga terjadi ketika digunakan dosis yang sudah standar. Kejadian spinal tinggi sering terjadi pada pasien obesitas, pendek, dan pasien yang sensitif terhadap anestesi. ${ }^{15}$

Mual dan muntah merupakan efek samping anestesi spinal yang lainnya. Kejadian mual muntah pada kelompok hiperbarik terjadi pada 5 dari 20 pasien dan kelompok isobarik terjadi pada 13 dari 20 pasien. Secara statistika dinyatakan bermakna sehingga disimpulkan bahwa bupivakain jenis isobarik lebih sering menyebabkan kejadian mual dan muntah. 
Penyebab mual dan muntah ini diperkirakan disebabkan oleh penurunan aliran darah ke otak akibat hipotensi. Oleh karena itu, dengan mengoreksi hipotensi yang terjadi biasanya akan mengurangi mual muntah. ${ }^{3}$

\section{Simpulan}

Kejadian hipotensi dan blokade sensorik lebih tinggi pada pengunaan anestesi spinal dengan kombinasi bupivakain 0,5\% isobarik $12,5 \mathrm{mg}$ dan fentanil $25 \mu \mathrm{g}$ dibanding dengan bupivakain $0,5 \%$ hiperbarik $12,5 \mathrm{mg}$ dan fentanil $25 \mu \mathrm{g}$. Terdapat dua kegunaan praktis yang dapat diaplikasikan; pertama bahwa bupivakain isobarik dapat digunakan untuk pasien yang akan menjalani seksio sesarea dengan metode combined spinal epidural (CSE) karena pasien akan duduk lebih lama setelah dilakukan anestesi spinal dan diharapkan analgesia yang adekuat tetap tercapai. Kedua, bahwa pasien dapat diposisikan trendelenburg untuk meningkatkan aliran balik vena sehingga mengurangi penurunan tekanan darah tanpa risiko terjadi spinal tinggi. Perlu dipertimbangkan juga dosis anestetik lokal yang digunakan karena dengan terjadi perubahan anatomi pada wanita hamil maka dosis yang dibutuhkan untuk menghasilkan blokade yang adekuat dapat dikurangi.

\section{Daftar Pustaka}

1. Frolich MA. Obstetric anesthesia. Dalam: Butterworth JF, Mackey DC, Wasnick JD, penyunting. Clinical anesthesiology. Edisi ke-5. New York: Mcgraw-Hill; 2013. hlm. 843-76.

2. Longdong JF, Redjeki IS, Wargahadibrata AH. Perbandingan efektivitas anestesi spinal menggunakan bupivakain isobarik dengan bupivakain hiperbarik pada pasien yang menjalani operasi abdomen bagian bawah. JAP. 2013;1(2):69-77.

3. Butterworth JF, Mackey DC, Wasnick JD. Spinal, epidural and caudal blocks. Dalam: Morgan GE, Mikhail MS, penyunting. Clinical anesthesiology. Edisi ke-5. New York: Mcgraw-Hill; 2013. hlm. 937-74.
4. Hallworth SP, Fernando R, Columb MO, Stocks GM. The effect of posture and baricity on the spread of intrathecal bupivacaine for elective caesarean delivery. Anesth Analg. 2005;100:1159-65.

5. Hocking G. Spinal anaesthetic spread. 2006 [diunduh 5 Juni 2015]. Tersedia dari: www.aagbi.org/sites/default/files/ 37-spinal-anesthetic-spread.

6. Imbelloni LE, Moreira AD, Gaspar FC, Gouveia MA, Cordeiro JA. Assessment of the densities of local anesthetics and their combination with adjuvants. an experimental study. Rev Bras Anestesiol. 2009;59(2):154-65.

7. Aftab S, Ali H, Zafar S, Sheikh M, Sultan ST. Intrathecal isobaric versus hyperbaric bupivacaine for elective caesarean section. Pak J Surg. 2007;23(4):296-301.

8. Vercauteren MP, Coppejans HC, Hoffmann VL, Saldien V, Andriansen HA. Small dose hyperbaric versus plain bupivacaine during spinal anesthesia for caesarean section. Anesth Analg. 1998;86:989-93.

9. Punshi GD, Afshan G. Spinal anaesthesia for caesarean section: plain vs hyperbaric bupivacaine. J Pak Med Assoc. 2012;62(8):807-11.

10. Loubert C, Hallworth S, Fernando R, Columb M, Patel N, Sarang K, dkk. Does the baricity of bupivacaine influence intrathecal spread in the prolonged sitting position before elective caesarean delivery? a prospective randomized controlled study. Anesth Analg. 2011;113(4):811-7.

11. Tyagi A, Kakkar A, Kumar S, Sethi AK, Salhotra R. $\mathrm{ED}_{50}$ of hyperbaric bupivacaine with fentanyl for caesarean delivery under combined spinal epidural in normotensive and preeclamptic patients. RAPM. 2012;37(1):40-4.

12. Simin A, Zahra F, Pouya HM, Reza T. Comparison the effect of ephedrine and phenylephrine in treatment of hypotension after spinal anesthesia during caesarean section. OJOG. 2012;2:192-6.

13. Bernards CM. Epidural and spinal anesthesia. Dalam: Barash PG, Cullen BF, Stoelting RK, Cahalan MK, Stock MC, 
Ahmado Okatria: Perbandingan Kombinasi Bupivakain 0,5\% Hiperbarik dan Fentanil dengan Bupivakain 0,5\% Isobarik

penyunting. Clinical anesthesia. Edisi ke-6. Philadelphia: Lippincot Williams \& Wilkins; 2009. hlm. 927-54.

14. Murthy HS, Murthy TNS, Muralidhar TS, Chandra NLU. Study of factors influencing oxygen desaturation during spinal anaesthesia. Indian $\mathrm{J}$ Anaesth. 2002;46(6):473-5.

15. Javed S, Hamid S, Amin F, Mahmood KT. Spinal anesthesia induced complications in caesarean section-a review. J Pharm Sci Res. 2011;3(10):1530-8. 